\title{
Thorium: Crustal Abundance, Joint Production, and Economic Availability*
}

\author{
Brett W Jordan ${ }^{1}$, Roderick G Eggert ${ }^{2}$, Brent W Dixon ${ }^{3}$, and Brett W Carlsen ${ }^{3}$ \\ ${ }^{1}$ brjordan@mines.edu, Colorado School of Mines, 816 15th Street Golden, Colorado 80401, \\ USA \\ ${ }^{2}$ Colorado School of Mines, 816 15th Street Golden, Colorado 80401, USA \\ ${ }^{3}$ Idaho National Engineering and Environmental Laboratory, PO Box 1625 Idaho Falls, \\ Idaho, USA
}

February 12, 2015

\begin{abstract}
Recently, interest in thorium's potential use in a nuclear fuel cycle has been renewed. Thorium is more abundant, at least on average, than uranium in the earth's crust and, therefore, could theoretically extend the use of nuclear energy technology beyond the economic limits of uranium resources. This paper provides an economic assessment of thorium availability by creating cumulative-availability and potential mining-industry cost curves, based on known thorium resources. These tools provide two perspectives on the economic availability of thorium. In the long term, physical quantities of thorium likely will not be a constraint on the development of a thorium fuel cycle. In the medium term, however, thorium supply may be limited by constraints associated with its production as a by-product of rare earth elements and heavy mineral sands. Environmental concerns, social issues, regulation, and technology also present issues for the medium and long term supply of thorium.
\end{abstract}

${ }^{*}$ We gratefully acknowledge the financial support of the US Department of Energy for project funding. 


\section{Introduction}

There is renewed interest in the commercialization of a thorium fuel cycle for generating nuclear power (International Atomic Energy Association (IAEA) 2005, 2012). Growth in electricity demand, particularly in developing countries, combined with the threat of climate change have driven new or renewed interest in a host of power generating alternatives. Such interest includes conventional and advanced nuclear reactors and fuel cycles, of which thorium is a potential option (IAEA, 2005). The benefits and drawbacks of adopting a thorium fuel cycle compared to a uranium fuel cycle continue to be studied, but wide-spread agreement has formed that thorium is, on average, three to four times more abundant than uranium in the earth's crust (Kademani et al., 2006). The implication is that thorium supply has the potential to last longer, or support a larger reactor deployment, than uranium supply. Crustal abundance, however, is an incomplete measure of potential supply. To draw a more complete conclusion about the potential supply of any resource, one must consider resource availability. This paper provides an assessment of the availability of thorium in the medium and long term.

Availability of any mineral resource can be defined in four dimensions. The geologic dimension, of which crustal abundance is a component, describes the physical quantity and characteristics of a resource. The technological dimension characterizes the ease or difficulty of recovering and purifying a resource. The social and political dimension of availability measures how resistant social and political institutions are to the recovering of a resource. Social and political resistance tend to increase as the environmental impact of a mine increases. Finally, the economic dimension measures whether or not a resource is profitable to recover. While these dimensions are interdependent, the focus of this paper will be on the economic measure of availability.

This analysis of economic availability uses two related analytical tools. The first is a cumulative availability curve (Yaksic and Tilton, 2009), which provides a perspective on availability over the longer term (decades). It is a plot of total resources grouped by the type of deposit and the associated costs of recovery. Analysis of the cumulative availability curve for thorium suggests that thorium cost could be comparable to historical average uranium prices. Thorium costs around this level should not be prohibitive to the development of a commercial fuel cycle.

The second tool, a potential mining-industry cost curve, illustrates availability over the medium term (some five to twenty years into the future). It is a more conventional, marketassessment tool, which plots the potential production rates of individual mines or deposits given capacity constraints and associated costs. In this study, we base the potential cost curve on known resources of thorium, essentially none of which are developed. The potential cost curve represents a medium-term perspective because the resources contained in the curve would take a number of years to be developed once (and only if) a market for thorium emerges. The potential cost curve highlights the role that by-product production plays in thorium availability. Likely sources of thorium are titanium-sand and rare-earth deposits, some of which would be the lowest-cost sources of thorium. However, by-product thorium supply depends on the profitability of the associated main products, titanium sands and rare 
earths.

The Background section below discusses briefly the potential demand for thorium and outlines issues relevant to its potential supply as a by-product. The Methodology and Data section describes the sources of data and the cost estimation method used in constructing the cumulative availability and potential cost curves. The Results section presents the outcomes from the cost estimation model by deposit or deposit type as well as the cumulative availability and potential cost curves. Finally, the Conclusions section places economic availability of thorium in the broader context of social, political and technical availability.

\section{Background}

Thorium's potential use as part of a nuclear fuel cycle has been known and studied for more than 50 years. Over this time, there have been experimental-scale applications in nuclear reactors, but thorium has never been utilized on a large, commercial scale. ${ }^{1}$ There are several common reasons given for why a thorium fuel cycle has not been commercialized. First, uranium resources, for the most part, have not limited the development of uranium fuel cycles (Ünak, 2000, Van Gosen et al., 2009). Second, technological hurdles exist that thorium must overcome. For example, thorium fuel fabrication and reprocessing technologies are not mature (IAEA, 2012). Third, some have argued that uranium has received more state support than thorium as nations looked to advance military goals alongside civilian goals (Hargraves and Moir, 2010). These three reasons are by no means a comprehensive listing. However, the drawbacks and merits of incorporating thorium into a nuclear fuel cycle are outside the scope of this paper's focus on thorium availability. Readers interested in issues related to the operations or back-end of a thorium based fuel cycle should refer to IAEA (2005) for a more comprehensive discussion.

Total historic thorium demand, and consequently supply, has been relatively small in terms of quantity. Thorium's primary commercial use until recently has been in mantles for gas lanterns. Over the last two decades thorium has been replaced by more inert materials in such non-nuclear applications (Gambogi, 2013). To meet limited thorium demand in the past, by-product supply has been largely adequate. ${ }^{2}$

The role of by-product production of thorium, or joint production more generally, is key to thorium's historic and future supply. Joint production refers to situations in which multiple products are produced from one operation. At a mine, joint production can be characterized by three types of relationships: main product, co-product and by-product. A main product is a material that contributes such a large portion of revenue to a mine that investment and operating decisions are based almost entirely on the market (prices and production costs) for this material. A by-product, by contrast, is a material whose revenue contributes such a small portion to the total revenue of the mine that the mine largely ignores the by-product market when making investment and production decisions. Because

${ }^{1}$ The World Nuclear Association's webpage on thorium includes a summary of past reactors (WNA, 2014).

${ }^{2}$ Main product thorium mines have existed. For example, Steenkampskraal, South Africa. 
by-products are produced as an indirect consequence of producing another resource, the only costs attributable to them are the additional costs incurred to separate and recover them from the main product of the mine. A by-product is recovered only if its price exceeds these additional costs. Finally, a co-product is a material whose own market, and that of one or more other materials, justifies mine decisions. For this study and in the interest of keeping the cost analysis simple, we consider thorium as either a main product or a by-product, although there might be instances of co-product thorium supply in the future.

Thorium's potential future supply could come in the form of main product, by-product or twice by-product (by-product of a by-product) production. Main product thorium could be supplied from thorium mines, as depicted on the bottom-most section of Figure 1. Byproduct thorium could potentially come from rare earth element mining and processing, as depicted starting in the middle section of Figure 1 and flowing down. And finally, twice by-product thorium could be derived as a by-product of rare earth elements, which in turn are a by-product of heavy mineral sand mining as shown starting at the top section of Figure 1 and flowing down.

As shown in the bottom-most section of Figure 1, thorium could be mined and processed as a main product from high-grade vein deposits of minerals such as thorite (a thorium silicate, $\mathrm{ThSiO}_{4}$ ). The capital investment and operating decisions to mine these deposits would be determined by the market developments for thorium (with minor consideration given to potential joint products). As thorium has never been recovered on a commercial scale from thorite, many of the high-grade sources of thorium could require further technological developments in order to be recoverable.

The middle section of Figure 1, depicting rare earth mining and processing, shows that thorium could be produced as a by-product from rare earth processing. Once thorium is concentrated, thorium could be further processed on the mine site, or the concentrate could be sold to a downstream producer. Due to its radioactive nature and lack of a thorium market today, thorium is considered a deleterious element or nuisance in rare earth deposits and is treated as waste at rare earth mines. The majority of rare earth elements ${ }^{3}$ are produced from the mineral bastnäsite (a rare-earth fluorocarbonate, $\mathrm{LaCO}_{3} \mathrm{~F}$ ). The most notable bastnäsite mines are the Bayan Obo mine ${ }^{4}$ in Inner Mongolia, China, and the Mountain Pass mine in California. The mineral monazite (a rare-earth phosphate, $\mathrm{LaPO}_{4}$ ) contributes more modest quantities of rare earth supply, but typically has higher thorium concentrations than deposits which are mined for bastnäsite. The Mount Weld mine of Western Australia, which due to a unique weathering process actually has very low thorium content (IAEA, 2011), is the largest single producer of main product REE supplier from monazite. In addition to these three large rare earth deposits and other mines inside of China, many deposits in various

\footnotetext{
${ }^{3}$ REEs with lower atomic weights, typically called "light" REEs are produced and consumed in much greater quantities than "heavy" REEs. A major source of heavy REEs are ion-absorbtion clays in southern China. These clays are not a suitable source of thorium.

${ }^{4}$ The Bayan Obo mine is a main product iron ore mine, but is also the largest single producer of rare earth elements in the world (Long et al., 2010). Thorium at Bayan Obo could be considered a twice by-product of rare earth elements and iron. However, the Bayan Obo case is relatively unique in this respect.
} 
Figure 1: Generic Process Flow for Thorium Supply by Source

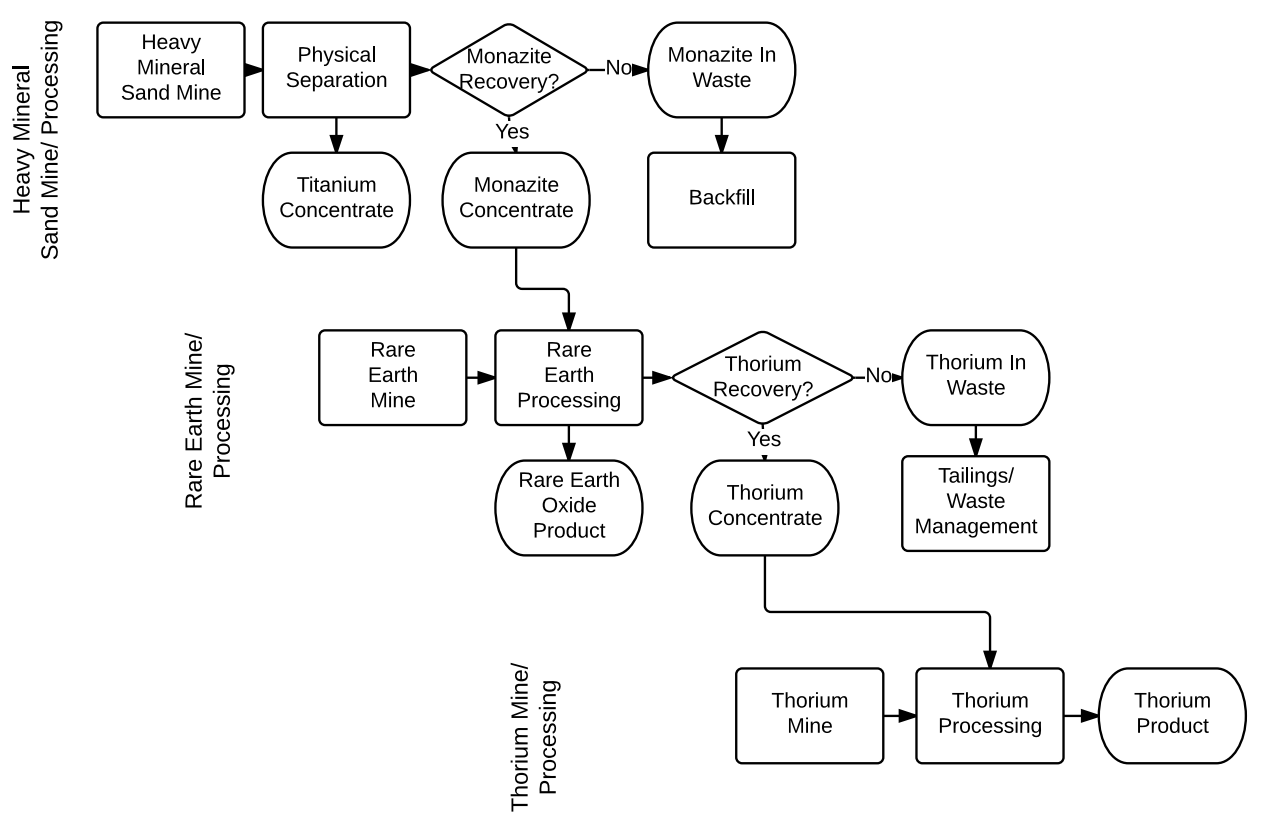

Source: Authors' Representation

This is a generic flowsheet designed to illustrate joint production relationships. These sources are inter-connected by the downward flows primarily to simplify the figure and avoid duplication.

stages of exploration could become rare earth mines. The capital investment and operating decisions of both the prospective and current rare earth operations will be almost completely dependent on the rare earth values recovered. In the absence of a thorium market, the presence of radioactive thorium negatively affects the attractiveness of developing a rare earth deposit into a mine. Therefore there is a current trend of developing rare earth mines with low thorium content. There is no publicly available information about a commercial scale technology for recovering thorium from bastnäsite ${ }^{5}$ deposits, but thorium has been recovered from monazite (principally from heavy mineral deposits) for many decades.

Finally, shown in the uppermost section of Figure 1, thorium could be produced as a twice by-product from titanium heavy mineral sand mines. While these mines would primarily be concerned with the recovery of titanium, market developments for rare earth elements (and

\footnotetext{
${ }^{5}$ Bastnäsite in its most common form does not contain thorium, but is frequently associated with minerals that do in "bastnäsite deposits".
} 
thorium) could entice such producers to install and operate monazite concentration circuits which could then be further processed by the mine or sold (in specific cases) to rare earth mines and processing facilities. Monazite typically has the highest specific gravity among minerals in these deposits in addition to unique magnetic properties. Thus concentration of monazite requires only physical separation methods (Ito et al., 1991, Ferron et al., 1991) and not more expensive chemical separation. Monazite concentrate then could be further processed to recover rare earth elements as described previously. Twice by-product recovery of thorium has occurred for some time in India (Barthel and Dahlkamp, 1992), which currently produces and stores thorium for probable future use in the country's nuclear program. Because of the long history of thorium recovery from these heavy mineral deposits and current recovery taking place in India, the technology to recover thorium from monazite (in heavy mineral deposits) is more mature than the technology to recover thorium contained in bastnäsite or thorite deposits.

\section{Methodology and Data}

This section describes the sources of data and the cost estimation method used in constructing the cumulative availability and mining-industry cost curves. We first describe the cumulative availability and mining-industry cost curves and their use in assessing the economic availability of thorium produced as a main product, by-product, or twice by-product. We then characterize the data used for the horizontal (quantity) axes of the cumulative availability and of the mining-industry cost curves. Finally, we describe the method for determining the vertical (cost) axis values, which are the same for both curves, and illustrate this method with an example deposit.

\subsection{The Cumulative Availability and Mining-industry Cost Curves}

The cumulative availability curve is a tool for assessing material availability over the longer term, decades into the future (Tilton, 2003). The curve represents the costs of production of a non-renewable resource over the total (or cumulative) quantity produced. The analysis holds technology and known resources fixed. The curve is positively sloped because higher prices justify the recovery of higher cost, resources. Yaksic and Tilton (2009) illustrate the use of the cumulative availability curve for the case of lithium. They note that availability is influenced by three types of factors. First, geologic factors determine the shape of the curve. For instance, a steep curve indicates that there are only small quantities of low cost resources. Second, the nature of demand will determine how quickly society moves along the curve (from lower to higher costs sources). Finally, the third group of factors shifts the curve through changes in technology or quantity of resources (due to exploration).

The cumulative availability curve that we construct includes an additional feature: estimated recovery costs for three different types of thorium production from the same resource (main product, by-product, and twice by-product).

It is important to emphasize that the horizontal axis of the cumulative availability curve, cumulative production, is a stock variable. This is in contrast to flow variables, such as annual or monthly production, which appear on the horizontal axis of a supply curve. Another 
important feature of the cumulative availability curve is that technology and known resources are held fixed, but other variables, such as global refining capacity are ignored. In this way, the curve presents an analysis of the economic long run, the time frame in which variables under direct control of the mining firm such as labor, capital and land are not constrained, but external variables such as known resources, government policy and the state of technology are fixed. However, at present or at any given point in time in the future, mining firms are faced with a situation where at least one variable under their control is fixed and they are therefore constrained by production capacities.

To provide an alternative perspective on thorium availability, one that utilizes both a flow variable for production and incorporates fixed capacity that mining firms face at any given time, we construct a potential mining-industry cost curve. This curve uses the same vertical axis as the cumulative availability curve, the average total cost of producing one kilogram of $99.99 \%$ thorium oxide. Each mine or deposit is presented on the mining-industry cost curve as a bar, the width of which represents that mine's annual thorium production capacity. In this way, the horizontal axis represents potential annual production capacity of the thorium industry as a whole. Using the potential cost curve is particularly relevant in our application, because if thorium is produced as a by-product then the quantities of thorium that can be produced will be constrained by the quantities of rare earths or heavy mineral sands produced.

Both the cumulative availability and mining-industry cost curves are presented and discussed in Section 4, Results.

\subsection{Data on Resources by Deposit Type}

The resource data for the horizontal axis of the cumulative availability curve reflect the best estimates to date of known and undiscovered resources. Every two years the Nuclear Energy Agency (NEA) and IAEA publish Uranium: Resources, Production and Demand commonly called The Red Book, which includes estimates of thorium resources. The NEA/IAEA categorize these resources into levels of geologic confidence (including undiscovered) for resources deemed to be recoverable at less than $\$ 80 / \mathrm{kg}$ (a cutoff also used in their assessment of uranium resources). It should be noted however that because there is little standardization in the classification of thorium resources, these figures are not likely comparable to standardized resource figures for other minerals, such as uranium. Apart from their classification by geologic confidence and recovery cost, the NEA/IAEA also groups thorium resources by five types of deposits: carbonatite, placer (heavy mineral sand), vein, alkaline, and "other" (NEA and IAEA, 2012).

\subsection{Data on Individual Deposits/Mines}

For the horizontal axis of the mining industry cost curve, the data are deposit-specific. Data on thorium grades, quantities and joint products were collected for a selected set of individual thorium deposits and operating heavy mineral sand and rare earth mines around the world. Included in the selected deposits and mines are: the thorium stockpile accumu-

lated by the United States government, major rare earth mines operating outside of China, a number of the operating heavy mineral sand mines globally (approximately $24 \%$ of world 
capacity), four rare earth projects that could come into commercial production before 2020, and six thorium deposits in the United States. Appendix B discusses what quantities of thorium might be recoverable if all heavy mineral sand and rare earth capacity were to be included. Deposits and mines were generally selected based on their potential to produce thorium and on information on thorium grades and main product production being available.

\subsection{Recovery Cost Model}

For the vertical axis of both the cumulative availability and mining-industry cost curves we develop a cost model for thorium recovery as a main product, by-product, and twice byproduct. To date, the only detailed attempt identified in the public domain to quantify the cost of thorium mining, milling and refining is Young et al. (1980). Young et al. (1980) used engineering-process-flow and discounted-cash-flow analysis to assess the costs of extracting thorium as a main product from deposits in the United States. Since the Young et al. (1980) study was conducted, the markets for rare earth elements have developed considerably as new end-uses for rare earth oxides (REOs) have developed. Such market developments could make it attractive for deposits to be developed primarily for their rare earth resources with thorium produced as a by-product. Depending on the deposit, considerable cost savings are associated with thorium being produced as a by-product as opposed to a main product.

To account for the effects of cost inflation since the Young et al. (1980) study was conducted, simple cost escalation factors were applied to modify the estimates from 1978 US dollars to 2013 US dollars. Details can be found in Appendix A. All costs presented in this paper are in 2013 US dollars.

\subsection{By-Product Cost Estimation Example: Bear Lodge, Wyoming}

The Bear Lodge deposit in northeastern Wyoming is currently being explored by Rare Element Resources, Ltd. as a potential rare earth mine. This deposit makes an excellent example to use for our by-product cost estimation method for several reasons: (1) the project is an advanced rare earth project in North America, with NI-43-101 compliant resource statements $^{6} ;(2)$ of prospective rare earth mines, it has a reasonable chance of coming into commercial production; and (3) the deposit was one considered by Young et al. (1980) to be a potential thorium main product mine. These features allow comparison between the Young et al. (1980) study's estimated main product cost and quantity and those estimated by this paper. Figure 2 shows a simplified process flow diagram for the proposed Bear Lodge rare earth mine and associated processing facilities along with a hypothetical thorium recovery circuit. $^{7}$

\footnotetext{
${ }^{6}$ A National Instrument (NI)-43-101 statement is one that complies with the Canadian Securities Administrators' set of standardized rules and guidelines for defining mineral resources and reserves for listing on Canadian stock exchanges.

${ }^{7}$ This example is hypothetical; Rare Element Resources has no announced plans to handle thorium in any way other than as a waste product.
} 
Figure 2: Proposed Bear Lodge Rare Earth Process with Hypothetical Thorium Circuit

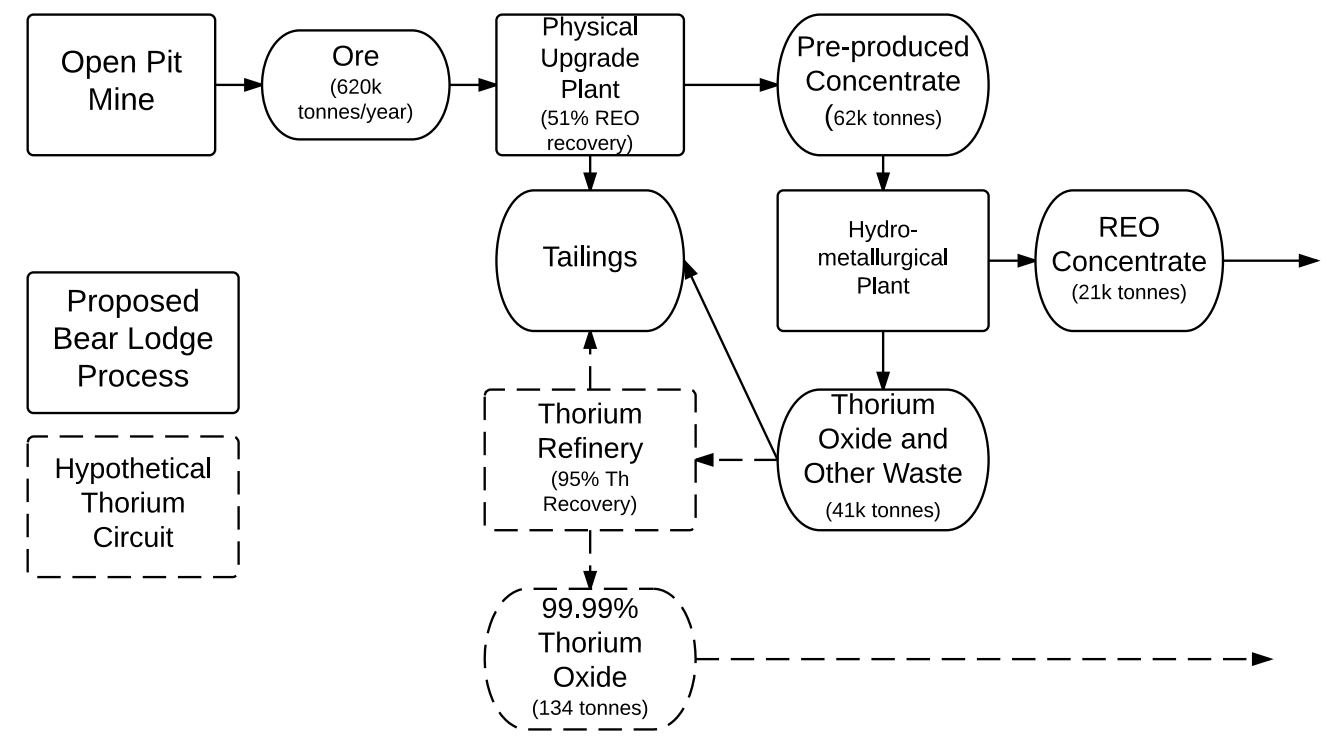

Source: Authors' Representation based on process flow information in Roche Engineering (2012) 
Bear Lodge's mine plan ${ }^{8}$ calls for 620,000 tonnes of ore per year to enter the physical separation plant. This ore, on average, contains 20,000 tonnes of rare earth oxide, and an unspecified quantity of thorium. The physical separation plant creates 62,000 tonnes of "preproduced concentrate" per year. Based on reported grades, the pre-produced concentrate contains 142 tonnes of thorium oxide. Next, the pre-produced concentrate is shipped to the hydrometallurgical plant which produces a final product of 21,000 tonnes of rare earth oxide concentrate. During processing at the hydrometallurgical plant, we assume all of the thorium is separated and combined with other material into a single waste stream. Therefore, a plant designed to recover all thorium from the waste stream would require a capacity of 41,000 tonnes of material per year. Thorium is assumed to be recovered and purified at a 95 percent rate (the rate used by Young et al. (1980)) from this waste material, yielding 134 tonnes of 99.99 percent purified thorium oxide product.

We use the capacity information from the materials flow described to scale the escalated costs for the hypothetical monazite recovery plant described in Young et al. (1980). There are two different factors required for this scaling calculation, one for fixed costs where economies of scale may exist and one for variable costs which change linearly with the quantity of ore processed. We use the following equation, typical in mining and chemical engineering cost studies (Darling, 2011, Green and Perry, 2008) to perform the scaling associated with fixed costs:

$$
\text { Cost }_{\text {new }}=\left(\text { Capacity }_{\text {New }} / \text { Capacity }_{\text {Old }}\right)^{0.7} \text { Cost }_{\text {Old }}
$$

where Cost $_{\text {new }}$ is the cost for the Bear Lodge Th recovery facility, Capacity $y_{\text {New }}$ is the required capacity of the Bear Lodge facility, and Capacityold and Costold are the capacity and costs, respectively, of the hypothetical Palmer recovery facility estimated by Young et al. (1980). The parameter 0.7 is a term related to economies of scale, and is based on the "seven-tenthsrule" in engineering cost estimation (Green and Perry, 2008, pp. 9:13-14). The scaled Bear Lodge costs can be found in Table A.2 of Appendix A. Next, capital costs of the hypothetical plant are annualized to Bear Lodge's assumed mine life, 19 years, using a fixed charge rate, which incorporates tax effects and discounting. For simplicity, the rate calculated by Young et al. (1980) for the Palmer recovery plant, 0.2338, is used here. ${ }^{9}$ After annual operating costs, annualized capital costs and unit production costs are discounted, these costs are escalated from 1978 dollars to 2013 dollars using appropriate escalation factors (See Appendix A for these factors and their sources). The escalated costs are presented in Table 1. Depreciable Assets are calculated by multiplying the fixed charge rate of 0.2338 by the Total Depreciable Capital Investment of $\$ 8,438,000$, found in Table A.2 of Appendix A. Working Capital of $\$ 700,000$ is the only non-depreciable asset, and is spread out over a 10 year period.

The final by-product cost of production for Bear Lodge, $\$ 92 / \mathrm{kg} \mathrm{ThO}_{2}$ is significantly

${ }^{8}$ See Roche Engineering (2012) for the Bear Lodge mine plan used in this study. While the Bear Lodge mine plan has since been modified, these changes would not materially change the conclusions of this analysis.

${ }^{9} \mathrm{~A}$ sensitivity analysis was conducted for this fixed charge rate. A doubling of the rate resulted in an average change in cost of $16 \%$ across deposits. A halving of the rate resulted in an average change of $10 \%$ across deposits. 
Table 1: Bear Lodge Scaled Annual Production Costs

\begin{tabular}{lc} 
Depreciable Assets $(\$ 000 \mathrm{~s})$ & 1,973 \\
Non-Depreciable Assets $(\$ 000 \mathrm{~s})$ & 70 \\
Operating Costs $(\$ 000 \mathrm{~s})$ & 10,302 \\
\hline Annual Production Costs $(\$ 000 \mathrm{~s})$ & 12,345 \\
Annual Production ('000 kgs) & 134 \\
\hline Levelized Production Cost $(\$ / \mathrm{kg})$ & 92
\end{tabular}

lower, as expected, than the escalated cost that Young et al. (1980) found for main product recovery from the same deposit, $\$ 345 / \mathrm{kg}$.

\section{Results}

This section presents the results of applying the cost estimation method described in the previous section for Bear Lodge to the other deposits selected for this study. The results are plotted on the cumulative availability and mining-industry cost curves. For both curves, we discuss the implications of the shape of the curves and the associated impact on availability. We then use a constructed demand scenario from Appendix C to illustrate how society might move along the curves. Finally, we discuss how the curves might shift as a result of new exploration or changes in technology.

\subsection{Cost Estimates for Individual Deposits/Mines}

A process similar to that described for Bear Lodge was applied to selected deposits globally that would produce thorium as a by-product or a twice by-product. The costs to recover thorium as a main product are escalated without other modification from Young et al. (1980). Table 2 shows a summary of the deposits included in the cost estimation, grouped by joint production relationships and ordered by unit production cost. The cost and capacity figures shown in Table 2 relate directly to those in Figure 4, the mining industry cost curve. Complete sources of data and the assumptions used to calculate cost for each of these deposits can be found in Jordan and Eggert (2014).

\subsection{Cost Estimates by Deposit Type}

In order to construct the cumulative availability curve, costs are assigned to the four deposit types categorized by the NEA/IAEA. ${ }^{10}$ Costs are further distinguished as either being main product costs, by-product costs, or twice by-product costs (only in the case of placer/ heavy mineral sands). For example, the Mountain Pass rare earth mine is a carbonatite deposit containing minor amounts of thorium, which could be produced as a

\footnotetext{
${ }^{10}$ There are some deposits which categorization is more ambiguous. When available, we assign deposits based on the deposit type listed on the IAEA ThDepot database. These deposits are Bokan Mountain, Mountain Pass, Bear Lodge, Mt. Weld, Hall Mountain, Wet Mountains, and Lemhi Pass.
} 
Table 2: Potential Sources of Thorium by Joint Product Relationship and Cost (2013 USD)

\begin{tabular}{|c|c|c|c|c|c|c|c|}
\hline & Deposit/Mine & Country & Owner & Status & Mine Life & Cost $(\$ / \mathrm{kg})$ & $\begin{array}{r}\text { Capacity } \\
\text { (tonnes/y) }\end{array}$ \\
\hline \multirow{6}{*}{ 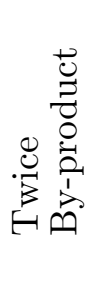 } & Richards Bay & S. Africa & RBM, Rio Tinto & Operating ${ }^{1}$ & 30 & 8 & 1683 \\
\hline & Murray Basin & Australia & Iluka & Operating & 6.5 & 8 & 859 \\
\hline & Eucla Basin & Australia & Iluka & Operating & 14 & 9 & 509 \\
\hline & Perth Basin & Australia & Iluka & Operating & 12 & 14 & 177 \\
\hline & Concord, Virginia & USA & Iluka & Operating & 20 & 19 & 93 \\
\hline & Orissa & India & Indian Rare Earths & Operating & $\mathrm{NA}^{2}$ & 19 & 240 \\
\hline \multirow{6}{*}{ 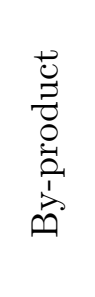 } & Steenkampskraal & S. Africa & Great Western & Pre-feasibility ${ }^{3}$ & 10 & 4 & 1176 \\
\hline & Bokan Mountain & USA & Ucore & $\mathrm{PEA}^{3}$ & 11 & 47 & 29 \\
\hline & Mountain Pass & USA & Molycorp & Operating & 30 & 76 & 67 \\
\hline & Bear Lodge & USA & Rare Element Res. & Pre-feasibility & 19 & 92 & 134 \\
\hline & Mt. Weld & Australia & Lynas & Operating & 20 & 128 & 94 \\
\hline & Araxá & Brazil & MBAC & Pre-feasibility & 40 & 197 & 373 \\
\hline \multirow{7}{*}{ 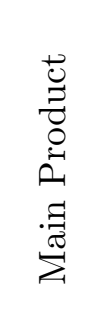 } & Stockplies & USA & US Government & "Deposit" 4 & $\mathrm{NA}^{5}$ & 18 & $3168^{5}$ \\
\hline & Hall Mountain & USA & & Deposit & 5 & 40 & 918 \\
\hline & Wet Mountains & USA & & Deposit & 5 & 49 & 693 \\
\hline & Lemhi Pass & USA & & Deposit & 14 & 85 & 1384 \\
\hline & Palmer & USA & & Deposit & 20 & 87 & 2918 \\
\hline & Bald Mountain & USA & & Deposit & 20 & 300 & 273 \\
\hline & Conway Granite & USA & & Deposit & 20 & 417 & 1289 \\
\hline
\end{tabular}

Sources for costs and capacity: By-product and twice by-product: this study's estimates and various public sources, see Jordan and Eggert (2014). Main product: escalated from Young et al. (1980).

${ }^{1}$ Operating heavy mineral sand or rare earth mine.

2 The Orrisa facility recovers rare earths and thorium from heavy mineral sands from across India. India's heavy mineral sand resources are extensive.

3 Three stages of feasibility studies are generally conducted in succession to evaluate the economic acceptability of a mining project. The first stage, the preliminary economic assessment (PEA) has a large degree of associated uncertainty, $+/-40-50 \%$. The next stage, the pre-feasibility study, increases the confidence to around $+/-25 \%$. The final stage is the definitive or bankable feasibility which is designed to reduce uncertainty to $+/-10 \%$.

4 The US thorium stockpile was disposed of in Nevada, but could be utilized if unearthed and refined.

5 The capacity and longevity of stockpiles will depend on demand. The quantity has been modified from Young et al. (1980) to reflect the quantity that is actually contained at the Nevada site (Hermes and Terry, 2006). 
by-product. ${ }^{11}$ Using the estimation process described earlier, the cost of producing pure thorium oxide as a by-product from Mountain Pass would be approximately $\$ 76 / \mathrm{kg}$. These assignments, organized by deposit type, are described in the text below and in Table 3.

By-product recovery costs were estimated for three carbonatite deposits, Mountain Pass, Mt. Weld and Araxá. As shown in Table 2, these by-product recovery costs ranged from $\$ 76$ to $\$ 197 / \mathrm{kg}$. No main product recovery costs were estimated for this deposit type because such estimation would require "bottom-up," mine engineering which is outside the scope of this study.

By-product and twice by-product recovery costs were estimated for six placer deposits. As shown in Table 2, costs for twice by-product recovery in these six placer deposits ranged from $\$ 8$ to $\$ 19 / \mathrm{kg}$. If however, thorium justifies recovery as a once by-product, all of the joint rare earth and thorium refining costs should be allocated to thorium. This adjustment raises recovery costs for these same five deposits to the range $\$ 65$ to $\$ 156 / \mathrm{kg}$. Finally, if thorium were to be produced as a main product from placer deposits, its recovery cost would jump dramatically. This recovery cost estimate has been escalated from the one conducted by Young et al. (1980), who found main product placer recovery so expensive relative to other sources of main product thorium they give only one lower bound estimate for recovery. While co-product relationships have been ignored, co-product costs would fall between main product and by-product costs.

Five vein type deposits have estimates for by-product and/or main product recovery costs. The basis for the by-product recovery cost range presented in Table 3 are the Bokan Mountain and Steenkampskraal deposits, while the basis for the main product recovery cost range are the Hall Mountain, Wet Mountains and Lemhi Pass deposits.

Only two alkaline rock type deposits were assessed, Bear Lodge as a by-product and as a main product (by (Young et al., 1980)) and Conway Granite as a main product. These estimates come directly from those presented in Table 2.

\subsection{Long Run Perspective: Thorium Cumulative Availability Curve}

Figure 3 is a graphical representation of the information in Table 3. Deposit types are sorted on the figure by the most likely and least costly means of recovery. Under this organization: twice by-product recovery from placer is the lowest cost, by-product from vein is the second least cost, and so-on. The cost values presented in the figure represent the higher value from the range in Table 3.

Particularly important in analyzing the cumulative availability curve is the curve's slope. For a discrete curve like the one estimated in this paper, slope is measured by how much of a cost increase is associated with a move from a lower to a higher cost source. In Figure 3, there is an approximate doubling of cost at each of these points. Yaksic and Tilton (2009) place lithium production costs in the context of the total cost of battery and vehicle manufacturing, of which lithium is a small component. Producers of batteries and vehicles are therefore more insensitive to lithium price changes. For thorium availability, the impact of cost escalation

\footnotetext{
${ }^{11}$ Mountain Pass has no current plans to recover thorium.
} 
Table 3: Potential Thorium Production Costs by Deposit Type (2013 USD)

\begin{tabular}{rcccc} 
Deposit Type & $\begin{array}{c}\text { World Thorium } \\
\text { Resources }^{1} \\
(1,000 \text { Tonnes })\end{array}$ & $\begin{array}{c}\text { Main Product } \\
\text { Cost }^{2} \\
(\$ / \mathrm{kg})\end{array}$ & $\begin{array}{c}\text { By-product } \\
\text { Cost }^{2} \\
(\$ / \mathrm{kg})\end{array}$ & $\begin{array}{c}\text { Twice By- } \\
\text { product Cost }^{2} \\
(\$ / \mathrm{kg})\end{array}$ \\
\hline Carbonatite & 1,900 & Note $A$ & $76-197$ & Note B \\
Placer deposits & 1,500 & $>760$ & $65-156$ & $8-19$ \\
Vein-type deposits & 1,300 & $40-85$ & $3-47$ & Note $B$ \\
Alkaline rocks & 1,120 & $345-417$ & 92 & Note B \\
Other & 258 & Note $A$ & Note $A$ & Note B \\
\hline
\end{tabular}

1 Data from (NEA and IAEA 2012)

2 This study's estimates

Note A: No resource in this category had cost estimated in this study.

Note B: Twice by-product production is only applicable in the case of placer deposits.

is more uncertain because there is no reliable point of reference. An approximation might be the market for uranium, which like lithium, makes up a fairly small portion of total costs of electricity generation in nuclear plants. Econometric studies have shown nuclear power utilities to be insensitive to uranium fuel price changes (Kahouli, 2011).

The curve in Figure 3 also illustrates the dramatic savings associated with producing thorium as a twice by-product of titanium and rare earth elements in placer deposits and as a by-product of rare earth elements in alkaline deposits. Cost savings for vein deposits is more modest because thorium in these deposits tends to be of a higher grade.

To illustrate how society might move along the availability curve, we draw from a global demand scenario constructed in Appendix C. In the scenario, there is a 45 year "ramp-up" period where thorium demand grows. After 45 years we assume demand remains constant. Demand is based on a fuel consumption of 10 tonnes/GWe*yr. After the 45 year ramp-up, we assume a total installed capacity of 373 GWe (see Appendix C), a 100\% capacity factor ${ }^{12}$, and a steady state, once through, limited recycle fuel cycle. Using these assumptions, cumulative demand is assessed at 100, 250 and 500 years after the beginning of the scenario. The calculated requirements are $0.313,0.872$, and 1.80 million tonnes of $99.99 \% \mathrm{ThO}_{2}$ for 100 , 250 and 500 years of reactor operation, respectively. Note that the units of demand are not the same as the units in the cumulative availability curve. The cumulative availability curve uses resources on the horizontal axis, which are an in-situ quantity. Before the two can be directly compared, we must assume some rate at which in-situ resources can be recovered and purified. Young et al. (1980) estimate thorium mine recovery rates for various deposits between $60 \%$ to $100 \%$, and mill recoveries between $40 \%$ and $98 \%$. Average refinery recovery rates are higher, $95 \%$ in most cases. For simplicity, we will assume the same recovery rate as the hypothetical Palmer mine, $56 \%$, but note the great deal of uncertainty around this rate.

\footnotetext{
${ }^{12}$ A $90 \%$ capacity factor is typically assumed for nuclear power. $100 \%$ is used here for simplicity.
} 
Figure 3: Cumulative Availability Curve: Thorium Resources by Deposit Type and Potential Production Costs

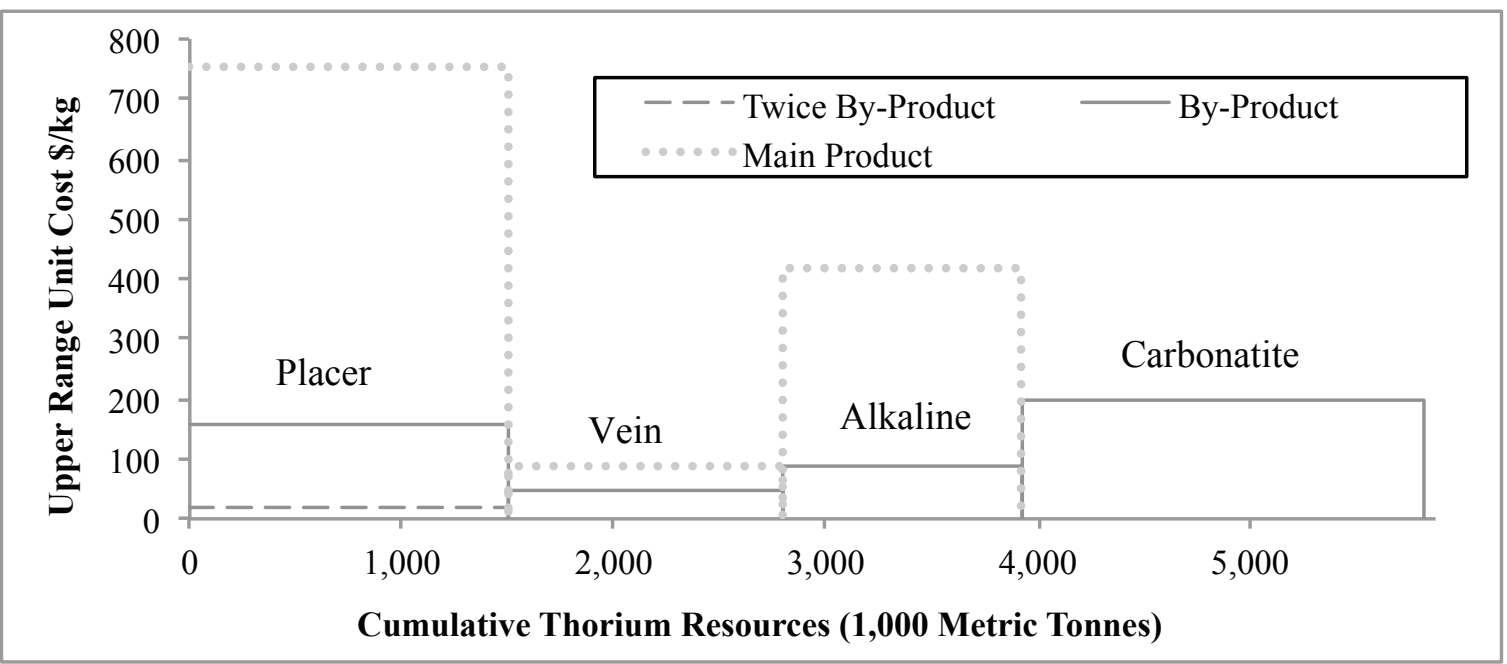

Source: Resource quantity data from (NEA and IAEA 2012). Cost data from this study: high value from each range in Table 3. Cost units are in 2013 US dollars.

With an assumed recovery rate of $56 \%$, resources from placer deposits are sufficient for the 100 year scenario. In the 250 year scenario, vein and placer deposits are required. Finally, in the 500 year scenario, known resources from placer, vein and alkaline deposits are required. This assumes the constant demand rate and adequate production of main product rare earth and titanium mines in order to recover thorium as a twice by-product.

Shifts in the curve will also impact availability. The effects of changing technology over time, which are not accounted for in the discussion above, will have implications for both demand and supply. The importance of these effects to material availability have been demonstrated for other metals such as copper in Tilton and Landsberg (1999). For demand, technological improvement could make reactors more efficient, reducing their consumption. For supply, technology could improve recovery rates or facilitate the discovery of new deposits. The effects of technology over long time periods, such as those calculated above, are especially relevant, but their exact magnitude is unknowable. Technological uncertainty limits a more precise estimate of longevity, but the cumulative availability analysis suggests that thorium will be recoverable on the order of centuries at a low cost if by-product and twice by-product sources are available. More importantly, the limitations motivate thinking about thorium supply in the medium term where technology is more predictable and supply constraints are accounted for.

The perspective of availability in Figure 3 is also limited because it presents by-product supply and main product supply equally as if all by-product supply were available. For such a presentation to be valid, there would need to be sufficient main product production of rare earths and titanium such that all by-product resources were accessible. The cumulative availability analysis ignores the fixed capacity constraints mines face at any given time. 
These constraints are particularly important in the mining industry where it takes many years to finance, explore, plan, permit and construct facilities.

\subsection{Medium Term Perspective: Potential Thorium Mining-Industry Cost Curve}

To present a different perspective on thorium availability, incorporating some of the limitations noted about the cumulative availability curve in Figure 3, this section develops a mining-industry cost curve for thorium. Applying the cost estimation methodology developed in this paper, the deposits summarized in Table 2 are plotted on the cost curve presented in Figure 4.

Figure 4: Potential ${ }^{1}$ Global Cost Curve for Selected Thorium Resources

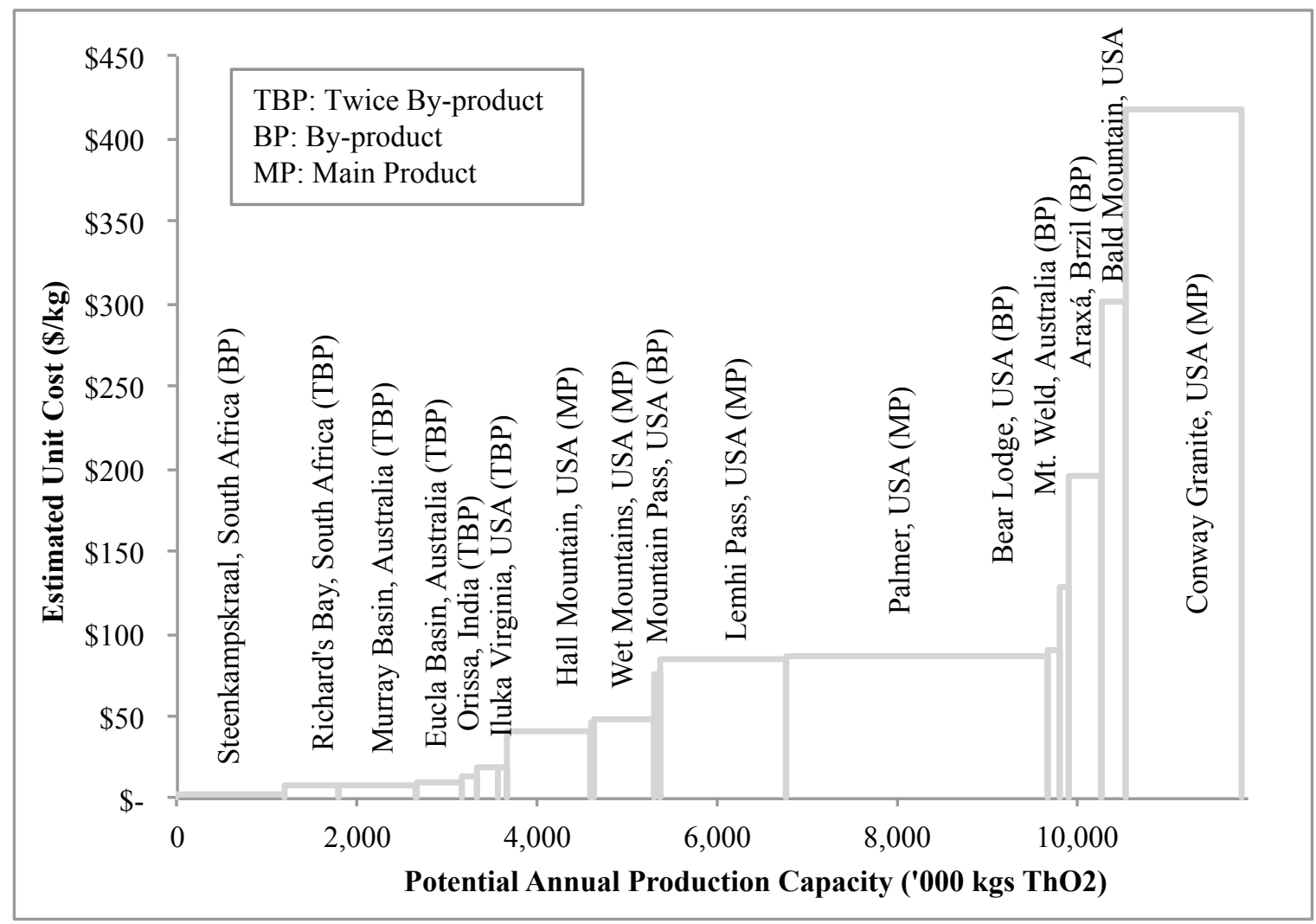

Source: This study, see Table 2. Cost units are in 2013 US dollars.

${ }^{1}$ Includes both currently operating mines and projects in development. Only the Orissa Sands Complex, India, has installed capacity for thorium recovery.

More interesting than the physical quantities of recoverable thorium at given costs are the sources of those quantities. Figure 4 shows that annual production of by-product thorium from rare earth mines such as Mount Weld, Mountain Pass, Bear Lodge and Araxá are expensive relative to twice by-product heavy mineral sources and even some main product thorium mines, such as Hall Mountain and Wet Mountains. This finding can partially be explained by the concentrated state of thorium waste in twice by-product operations, but 
more importantly calls attention to the fact that thorium is an undesirable nuisance element in rare earth mines. It is not uncommon for rare earth projects to advertise their low thorium content as a benefit of their deposit over others. If demand for thorium arises, the desire to seek thorium-poor deposits may change, but absent this demand, deposits with low thorium concentrations may be more likely to be developed.

The Steenkampskral deposit historically was one of the only main product thorium mines in the world and was profitable due to its very high grades. The low cost of the Richards Bay is due primarily to its large scale. The Richard's Bay mine also produced thorium until 1994. The Iluka heavy mineral sand mines of Australia, Murray Bay, Eucla Basin, and Perth Basin, have relatively low costs because of the assumed concentration of monazite entering the hypothetical rare earth and thorium separation plant. This concentration is assumed to be the same as the Orissa Sands Complex in India. ${ }^{13}$ Mt. Weld has high estimated costs due to the low grade of thorium in the rare earth separation plant feed (40\% REO, 0.13-0.16\% ThO2). While the Araxá deposit has a $0.10 \%$ grade of thorium in-situ, the processing plan for the proposed mine does not include a physical separation plant, and the run of mine material will enter directly into the chemical separation plant leading to a large quantity of other waste material that thorium must be further separated from.

The cost to produce thorium rises slowly, moving from left to right in Figure 4, as more deposits are required to meet a higher levels of annual demand, but remains below $\$ 20 / \mathrm{kg}$ until the first main product mine, Hall Mountain, must enter production to meet demand. Hall Mountain has twice the production costs of the cheaper, by-product and twice by-product, sources of supply. However, as noted in Appendix B, more potential annual thorium supply from heavy mineral sand mines is likely to be available than is included in the selected deposits for Figure 4.

To place the mining-industry cost curve into context of annual quantities demanded, we again draw from the scenario developed in Appendix C. In this scenario, maximum annual demand for thorium is calculated to be 3,730 tonnes $99.99 \% \mathrm{ThO}_{2}$ per year. This maximum, plotted on the mining-industry cost curve, is presented in Figure 5.

Figure 5 shows that even the peak level of annual demand from the constructed scenario can be met from the selected by-product and twice by-product sources of thorium and only one main product mine, Hall Mountain. However, the curve presented in Figure 5 does not incorporate all potential by-product production from rare earth and heavy mineral sand mines, as noted in Appendix B. The inclusion of omitted by-product production could meet demand without the need for more expensive main product mines, provided that omitted mines are similar in terms of costs and quantities to those included. Including additional sources would add additional "bars" to the curve, widening it overall. This does not override the basic point that for these sources to be low cost, thorium must be produced as a by-

\footnotetext{
${ }^{13}$ As the Orissa Sands Complex is currently the only known facility that concentrates monazite from heavy mineral sands before recovering thorium, it could serve as a model for other such plants. These plants could experience similar recovery factors. See Jordan and Eggert (2014) Appendix D and E for discussion of these assumptions.
} 
Figure 5: Mining-industry Cost Curve with Constructed Demand Scenario

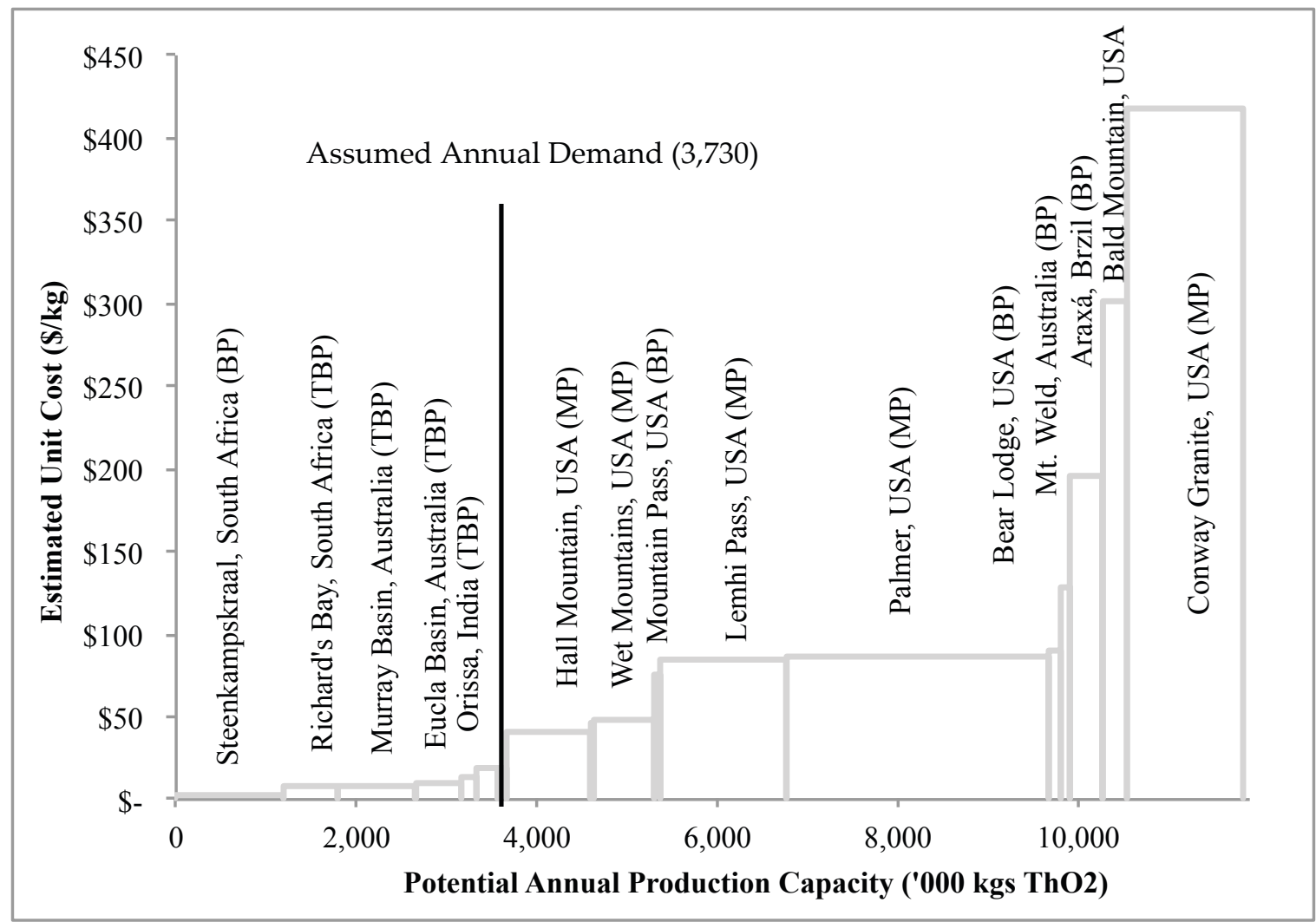

Source: This study, see Table 2. Demand is calculated by assuming a 10 tonnes of $\mathrm{ThO}_{2}$ are required per GWe per year, and a total installed global capacity of 373 GWe. See Appendix C.

product or as a by-product of a by-product.

While by-product or twice by-product thorium could serve as an important (or sole) source of supply under certain scenarios, main product thorium mining has occurred historically and may be required again if demand is large. Main product thorium mining might also be required if the market for rare earth elements does not sufficiently justify recovery from heavy mineral sand deposits or if heavy mineral sand producers are simply not interested in deviating from their core business.

The mining-industry cost curve will also be affected by the same shifting factors as discussed with cumulative availability, namely technology and exploration.

\section{Conclusions}

Thorium is estimated to be between three to four times more abundant than uranium in the earth's crust and has been identified around the globe in vein, placer, and carbonatite deposits and is almost always associated with rare earth elements as well as titanium minerals 
in the case of heavy mineral deposits. From the cumulative availability curve estimated in this study, sufficient quantities of thorium should be recoverable for many centuries at a cost that is unlikely to impede its use as a nuclear fuel. In the medium term, thorium availability may be more limited from by-product production constraints associated with rare earth and heavy mineral sand mining. In both the medium and long term; social, political and environmental considerations and technology could present issues for thorium supply.

Though we have found thorium production from by-product and twice by-product supply to likely be sufficient to meet the scenario of demand at a relatively low cost, several nuances are important to note. If rare earth producers continue the recent trend and seek less thorium-enriched sources of rare earth elements, then thorium may need to be produced as a direct by-product of heavy mineral sand operations rather than a by-product of a by-product. Such a development would involve a dramatic increase in recovery costs.

While not the direct focus of this paper, the other constraints to thorium availability (social, political, and environmental issues and the state of technology) are also important. Thorium is considered a nuisance material for rare earth operations because its radioactive presence can induce more stringent environmental regulations and increase the cost of tailings management. These concerns likely will persist into the future. Potential constraints also exist because of existing thorium recovery technology. Producing thorium at a large, commercial scale will likely require additional research and technological development which historically has received little investment.

Based on the findings of this study, it is unlikely that the potential development of a thorium based fuel cycle will be undermined by physical quantities of thorium resources or by the costs of extracting those resources. Current figures suggest that five to six million tonnes of thorium resources exist globally and these resources are found by this paper, given our demand scenario, to be physically sufficient for centuries. A significant portion of global thorium resources are contained in placer monazite, a supply source with some history of thorium recovery. Finally, thorium recovery costs are unlikely to be a major portion of total costs for plants, provided that thorium can be produced as a twice by-product, by-product or even, in select cases, as a main product.

A tremendous amount of uncertainty surrounds the future demand for thorium. A number of competing proposals for reactor designs, fuel configurations, and reprocessing options exist. On the front-end, it is uncertain how many more thorium-bearing deposits will be discovered, what kind of recovery technology will be developed, how political and social institutions could respond to thorium mining, or how mining firms will be react to a demand for thorium. What does seem to be clear is that, although thorium does not appear to a limiting factor for development of thorium-based nuclear fuel cycles, its availability is far more complex than its crustal abundance. 
We would like to thank Bradley Van Gosen of the USGS for his help and insight in preparing this paper as well as comments from John Tilton of the Colorado School of Mines and those of an anonymous reviewer. All errors however, are our own.

Barthel, F. and F. Dahlkamp (1992). Thorium deposits and their availability, IAEATECDOC-650. New developments in uranium exploration, resources, production and demand, 104-115. Available at: http://www-pub.iaea.org/MTCD/publications/PDF/te_ $0650 \cdot \mathrm{pdf}$.

Darling, P. (2011). SME Mining engineering handbook, Volume 1. Society for Mining, Metallurgy and Exploration.

Ferron, C. J., S. M. Bulatovic, and R. S. Salter (1991). Beneficiation of rare earth oxide minerals. In Materials Science Forum, Volume 70, pp. 251-270. Trans Tech Publications. DOI: $10.4028 /$ www.scientific.net/msf.70-72.251.

Gambogi, J. (2013). Thorium. Minerals Yearbook 2011, 76.1-76.3. Accessed on July 30, 2013. Available at: http://minerals.usgs.gov/minerals/pubs/commodity/thorium/ myb1-2011-thori.pdf.

Green, D. W. and R. H. Perry (2008). SME Mining Engineering Handbook (8th ed.). McGraw-Hill, New York.

Hargraves, R. and R. Moir (2010). Liquid fluoride thorium reactors an old idea in nuclear power gets reexamined. American Scientist 98(4), 304. Available at: http://www.americanscientist.org/issues/feature/2010/4/ liquid-fluoride-thorium-reactors.

Hermes, W. and J. Terry (2006). Removing the source term - thorium nitrate disposal at the Nevada test site. Oak Ridge National Laboratory, Knoxville: Health Physics Society. Available at: http://web.ornl.gov/ webworks/cppr/y2001/pres/125373.pdf.

IAEA (2005). Thorium fuel cycle-potential benefits and challenges, IAEA-TECDOC-1450. Technical report, International Atomic Energy Agency, Vienna. Available at: http:// www-pub.iaea.org/mtcd/publications/pdf/te_1450_web.pdf.

IAEA (2011). Radiation safety aspects of a proposed rare earths processing facility (the Lynas project). International Atomic Energy Agency, Vienna. Available at: http://www . iaea.org/sites/default/files/lynas-report2011.pdf.

IAEA (2012). Role of thorium to supplement fuel cycles of future nuclear energy systems, IAEA-TECDOC-1540. Technical report, International Atomic Energy Agency, Vienna.

Ito, S., H. Yotsumoto, and H. Sakamoto (1991). Magnetic separation of monazite and xenotime. In Materials Science Forum, Volume 70, pp. 279-300. Trans Tech Publications. DOI: $10.4028 /$ www.scientific.net/msf .70-72.279. 
Jordan, B. and R. Eggert (2014). An assessment of the costs, opportunities and challenges for the front-end of a thorium based fuel cycle. Technical report, Colorado School of Mines, Golden, CO.

Kademani, B., V. Kumar, A. Sagar, and A. Kumar (2006). World literature on thorium research: A scientometric study based on science citation index. Scientometrics $69(2)$, $347-364$.

Kahouli, S. (2011, jan). Re-examining uranium supply and demand: New insights. Energy Policy 39(1), 358-376. DOI: 10.1016/j.enpol.2010.10.007.

Long, K., B. Van Gosen, N. Foley, and D. Cordier (2010). The principal rare earth elements deposits of the United StatesA summary of domestic deposits and a global perspective:. US Geological Survey. Available at http://pubs.usgs.gov/sir/2010/5220/.

NEA and IAEA (2012). Uranium 2011: Resources, Production and Demand. Nuclear Energy Agency, Paris and International Atomic Energy Agency, Vienna.

Roche Engineering (2012, April). Technical Report on the Mineral Reserves and Development of the Bull Hill Mine. Roche Engineering. Available via sedar.com.

Tilton, J. E. (2003). On Borrowed Time: Assessing the Threat of Mineral Depletion. Resources for the Future, Washington, DC.

Tilton, J. E. and H. H. Landsberg (1999). Innovation, productivity growth, and the survival of the us copper industry. Productivity in Natural Resource Industries; Improvement through Innovation, 109-139. Available at: http://www.rff.org/Documents/ RFF-DP-97-41.pdf.

Ünak, T. (2000). What is the potential use of thorium in the future energy production technology? Progress in nuclear energy 37(1), 137-144. DOI: 10.1016/s0149-1970(00) 00038-x.

Van Gosen, B. S., V. S. Gillerman, and T. J. Armbrustmacher (2009). Thorium Deposits of the United States-energy Resources for the Future? US Geological Survey. Available at: http://pubs.usgs.gov/circ/1336.

Wigeland, R., T. Taiwo, H. Ludewig, M. Todosow, W. Halsey, J. Gehim, R. Jubin, et al. (2014). Nuclear fuel cycle evaluation and screening final report, INL/EXT-1431465. Technical report, Idaho National Laboratory, Idaho Falls, ID. Available at: https://inlportal.inl.gov/portal/server.pt/community/nuclear_science_and_ technology/337/nuclear_fuel_cycle_evaluation_and_screening_final_report/ 11118.

WNA (2014). Thorium. World Nuclear Association. Accessed on Jan 20, 2015. Available at: http://www.world-nuclear.org/info/Current-and-Future-Generation/ Thorium/\#3. 
Yaksic, A. and J. E. Tilton (2009). Using the cumulative availability curve to assess the threat of mineral depletion: The case of lithium. Resources Policy 34(4), 185-194. DOI: $10.1016 / j$.resourpol .2009 .05 .002 .

Young, J., C. Bloomster, W. Enderlin, M. Morgenstern, M. Ballinger, M. Drost, and S. Weakley (1980). Economics of large-scale thorium oxide production: assessment of domestic resources. Technical report, Battelle Pacific Northwest Labs., Richland, WA. 


\section{Appendix A Cost Estimation}

Table A.1 presents the escalation factors (and their sources) that were used in this study to convert Young et al. (1980) estimates', which are in 1978 dollars, to 2013 dollars which are the basis of this study. Cost items for the hypothetical thorium recovery plant are grouped by their corresponding escalation factors.

Table A.2 presents each cost item for the estimated Bear Lodge by-product thorium recovery facility and the scale factor used to scale the cost item from the escalated hypothetical plant cost. Interested readers should refer to Jordan and Eggert (2014) for complete documentation on the cost estimation for all deposits.

The scaling factor used in all Table A.2 is calculated using:

$$
\left(\text { DailyCapacity }_{\text {New }} / \text { DailyCapacityold }^{0.7}=(111 / 272)^{0.7}=0.53\right.
$$

Where Capacity $_{\text {New }}$ is the required capacity of the Bear Lodge facility, and Capacityold is the capacity of the hypothetical Palmer recovery facility estimated by Young et al. (1980). The parameter 0.7 is term related to economies of scale, and is the same one used by Young et al. (1980) and described in (Green and Perry, 2008, p. 9-13:14). For costs that scale linearly with plant size, the factor .41 was used (the ratio of "new" and "old" capacity). Finally, some costs are assumed to be fixed regardless of plant size.

The values marked with an asterisk $\left(^{*}\right)$ in Table A.2, Total Depreciable Capital Investment, Working Capital, and Total Annual Operating Costs are used as inputs into Table A.3. Total Depreciable Capital Investment is multiplied by the fixed charge rate of 0.2338 and Working Capital is annualized linearly over 10 years.

\section{Appendix B Context for Sample Deposits}

Because the medium term supply estimates presented in this paper are for a limited number of selected resources, they do not capture the full extent of estimated global resources. Table B.1 presents the resources that have been estimated as part of NEA/IAEAs Red Book alongside the life of mine (LOM) production included in this study. The LOM production is calculated by multiplying the assumed annual production of a given resource by its anticipated mine life. The table shows that less than $6 \%$ of global thorium resources are included in the cost analysis.

Measuring thorium in terms of known and estimated resources has limitations in putting included resources into context. Demand for titanium and rare earth elements may continue to drive the discovery of thorium bearing deposits. This would imply that $6.0 \%$ should be considered an upper bound of included resources. However, it is uncertain how costly and therefore how available these other resources may be.

Table B.1 also does not distinguish potential main product sources of production from potential by-product and twice by-product sources. This distinction is important as byproduct thorium recovery would be derived from titanium and rare earth markets and, in the medium term, supply of these products would be limited by installed capacity. On the other hand, by-product supply could likely come online more quickly than main product sources 
Table A.1: Escalation Factors and Sources by Cost Item

\begin{tabular}{|c|c|c|}
\hline Cost Item & Factor & Source \\
\hline $\begin{array}{l}\text { Equipment } \\
\text { Buildings and Equipment } \\
\text { Effluent Control Buildings \& Equipm } \\
\text { Exploration } \\
\text { Mine Equipment Replacement } \\
\text { Mill Equipment Replacement } \\
\text { Mine/Mill Effluent Control } \\
\text { Sulfuric Acid Plant Buildings \& Equi } \\
\text { Spare Parts Inventory } \\
\text { Contingency }\end{array}$ & 3.12 & $\begin{array}{l}\text { Marshal and Swift Mining and Milling Equip- } \\
\text { ment Cost Index, Equipment }\end{array}$ \\
\hline $\begin{array}{l}\text { Construction } \\
\text { Mine Tailings Pond } \\
\text { Development } \\
\text { Mill Tailings Pond } \\
\text { Access Road } \\
\text { Tailings Pond } \\
\text { Waste Sludge Landfill }\end{array}$ & 2.96 & $\begin{array}{l}\text { Bureau of Labor \& Statistics (BLS)-Stage of } \\
\text { processing-Construction }\end{array}$ \\
\hline $\begin{array}{l}\text { Professional Services } \\
\text { Environmental Impact } \\
\text { Exploration } \\
\text { Feasibility Study } \\
\text { Laboratory Charges }\end{array}$ & 3.87 & BLS- ECI-Professional and Related \\
\hline $\begin{array}{l}\text { Miscellaneous } \\
\text { Land } \\
\text { Development } \\
\text { Working Capital } \\
\text { Maintenance and Repairs } \\
\text { Sulfuric Acid Plant Op Costs } \\
\text { Water }\end{array}$ & 3.43 & $\begin{array}{l}\text { Federal Reserve Economic Data (FRED) } \\
\text { Consumer Price Index for All Urban Con- } \\
\text { sumers: All Items }\end{array}$ \\
\hline $\begin{array}{l}\text { Labor-Mining } \\
\text { Mine Labor Costs } \\
\text { Mill Labor } \\
\text { Operating Labor }\end{array}$ & 3.54 & $\begin{array}{l}\text { FRED Average Hourly Earnings of Produc- } \\
\text { tion and Nonsupervisory Employees: Mining } \\
\text { and Logging }\end{array}$ \\
\hline $\begin{array}{l}\text { Supplies } \\
\text { Materials and Supplies } \\
\text { Mill Materials and Supplies }\end{array}$ & 2.51 & BLS-Stage of processing-Supplies \\
\hline $\begin{array}{l}\text { Chemical Supervision \& Engineering } \\
\text { Mill/Refinery Supervision } \\
\text { Mill/Refinery Overhead } \\
\text { Mill/Refinery Administrative Costs }\end{array}$ & 1.97 & $\begin{array}{l}\text { Chemical Engineering Magazine, Plant Cost } \\
\text { Index, Engineering and Supervision }\end{array}$ \\
\hline $\begin{array}{l}\text { Chemicals } \\
\text { Refinery/Mill Operating Supplies } \\
\text { Refinery/Mill Reagents }\end{array}$ & 2.97 & $\begin{array}{l}\text { Marshal and Swift Mining and Milling Equip- } \\
\text { ment Cost, Chemicals }\end{array}$ \\
\hline $\begin{array}{l}\text { Diesel Fuel } \\
\text { Fuel Oil } \\
\text { Diesel Fuel }\end{array}$ & 4.64 & BLS-Fuels and related products and power \\
\hline Electricity & 2.82 & BLS- Commercial electric power \\
\hline
\end{tabular}


Table A.2: Scaled Hypothetical Thorium Recovery Plant to Bear Lodge Capacity

\begin{tabular}{|c|c|c|c|}
\hline & Hypth. Plant $\$ 000$ s & Resize Factor & Bear Lodge $\$ 000$ s \\
\hline \multicolumn{4}{|l|}{ Capital Expenditures } \\
\hline \multicolumn{4}{|l|}{ Refinery Or Mill Capital Cost } \\
\hline Building and Equipment & 10,949 & 0.53 & 5,847 \\
\hline Effluent Control Buildings \& Equipment & 456 & 0.53 & 243 \\
\hline Feasibility Study & 387 & 1 & 387 \\
\hline Environmental Impact & 387 & 1 & 387 \\
\hline Contingency & 1,564 & 0.53 & 835 \\
\hline Tailings Pond & 1,383 & 0.53 & 739 \\
\hline Total Depreciable Capital Investment & 15,126 & & $8,438^{*}$ \\
\hline Working Capital & 1,716 & 0.41 & $700^{*}$ \\
\hline Total Capital Investment & 16,842 & & 9,138 \\
\hline \multicolumn{4}{|l|}{ Operating Expenditures } \\
\hline Operating Labor & 2,488 & 0.53 & 1,329 \\
\hline Supervision & 207 & 0.53 & 111 \\
\hline Maintenance and Repairs & 1,503 & 0.53 & 803 \\
\hline Operating Supplies & 507 & 0.41 & 207 \\
\hline Laboratory Charges & 406 & 1 & 406 \\
\hline Total Direct Costs & 5,112 & & 2,856 \\
\hline \multicolumn{4}{|l|}{ Indirect Costs } \\
\hline Plant Overhead & 2,304 & 0.53 & 1,230 \\
\hline Administrative Costs & 576 & 0.53 & 308 \\
\hline Total Indirect Costs & 2,880 & & 1,538 \\
\hline Total Fixed Operating Costs & 7,992 & & 4,393 \\
\hline \multicolumn{4}{|l|}{ Variable Operating Costs } \\
\hline Reagents & 7,401 & 0.41 & 3,021 \\
\hline Utilities & 2,858 & 0.53 & 1,526 \\
\hline Transportation & 2,549 & 0 & \\
\hline Total Annual Operating Costs & 20,800 & & $10,302^{*}$ \\
\hline
\end{tabular}

Table A.3: Bear Lodge Scaled Production Costs

\begin{tabular}{lc} 
Depreciable Assets $(\$ 000 \mathrm{~s})$ & 1,973 \\
Non-Depreciable Assets $(\$ 000 \mathrm{~s})$ & 70 \\
Annual Operating Costs $(\$ 000 \mathrm{~s})$ & 10,302 \\
\hline Annual Production Cotsts $(\$ 000 \mathrm{~s})$ & 12,345 \\
Annual Production $(' 000 \mathrm{kgs})$ & 134 \\
\hline Levelized Production Cost $(\$ / \mathrm{kg})$ & 92
\end{tabular}


Table B.1: Selected and Total Estimated Thorium Resources by Country

\begin{tabular}{lllr}
\hline & $\begin{array}{l}\text { Low-Range } \\
\text { Estimate }^{1} \\
\text { (Tonnes) }\end{array}$ & $\begin{array}{l}\text { LOM Production \% of Total Estimated Resources } \\
\text { Included in this } \\
\text { Study }^{2} \text { (Tonnes) }\end{array}$ & \\
\hline India & 846,500 & 12,632 & $1.50 \%$ \\
Turkey & 744,000 & & $2.60 \%$ \\
Brazil & 606,000 & 15,713 & $3.60 \%$ \\
Australia & 521,000 & 18,622 & $41.60 \%$ \\
United States & 434,000 & 180,384 & \\
Egypt & 380,000 & & $61.00 \%$ \\
Norway & 320,000 & & \\
Venezuela & 300,000 & & \\
Canada & 172,000 & & \\
Russia & 155,000 & & \\
South Africa & 148,000 & 90,306 & \\
China & 100,000 & & \\
Rest of World & 581,300 & & \\
\hline Total & $5,307,800$ & 317,657 & \\
\hline
\end{tabular}

${ }^{1}$ Data from (NEA and IAEA, 2012)

${ }^{2}$ This study

due to smaller capital requirements. To assess these medium term effects, we calculate the potential quantities that have been excluded from the industry cost curve. Table B.2 below shows the quantity of main product supply accounted for in this analysis compared to the global supply of these main products recorded by the USGS.

Ilmenite and rutile are titanium bearing minerals that are frequently recovered together from heavy mineral sand operations and so by-product thorium cannot be attributed to one or the other. Rare earth mines are also broken into two categories, REO Current Production and REO Unutilized Capacity at Operating Mines. This distinction accounts for the fact that the included potential thorium production in the analysis is estimated based on the installed capacity of the Mt. Weld and Mountain Pass mines rather than their actual 2011 production. The percent of main product supply included in the analysis is calculated from USGS estimates, and this number implies a certain amount of potential thorium supply that has been excluded from the analysis, approximately 7,968 tonnes per year or 246,805 tonnes over the life of the excluded mines. These figures rely on the assumption that titanium and rare earth mines that have been excluded from the cost and availability curve analysis are similar in thorium grade, thorium tonnage and mine life to mines that have been included. In reality, mines included in the curves were chosen specifically for their potential to produce thorium and not for their being representative of other main product mines. 
Table B.2: Thorium Contained in Current REO and Titanium Mine Production

\begin{tabular}{|c|c|c|c|c|c|c|c|}
\hline Main Product & $\begin{array}{l}\text { Tonnes } \\
\text { Thorium } / \mathrm{y}^{1}\end{array}$ & $\begin{array}{l}\text { Life of Mine } \\
\text { (LOM) } \\
\text { Thorium } \\
\text { Production }^{1}\end{array}$ & $\begin{array}{l}\text { Main Product } \\
\text { Mine Supply } \\
\text { Included in } \\
\text { Analysis }^{2}\end{array}$ & $\begin{array}{l}\text { Total Main } \\
\text { Product Sup- } \\
\text { ply in } 2011^{2,3}\end{array}$ & $\begin{array}{l}\text { \% Main Prod- } \\
\text { uct Supply } \\
\text { Included in } \\
\text { Analysis }^{1}\end{array}$ & $\begin{array}{l}\text { Implied } \\
\text { Thorium } \\
\text { Excluded } \\
{\text { (Tonnes } / y)^{1}}^{1}\end{array}$ & $\begin{array}{l}\text { Implied } \\
\text { Thorium } \\
\text { Excluded } \\
(\mathrm{LOM})^{1}\end{array}$ \\
\hline Ilmenite & $\begin{array}{l}\text { See Titanium } \\
\text { Total }\end{array}$ & $\begin{array}{l}\text { See Titanium } \\
\text { Total }\end{array}$ & 674,100 & $5,870,000$ & $10.50 \%$ & & \\
\hline $\begin{array}{l}\text { Rutile } \\
\text { Titanium Slag }\end{array}$ & 598 & 50,495 & $\begin{array}{l}468,600 \\
970,000\end{array}$ & $\begin{array}{l}764,000 \\
2,210,000\end{array}$ & $\begin{array}{l}59.40 \% \\
43.90 \%\end{array}$ & & \\
\hline $\begin{array}{l}\text { Titanium Total } \\
\text { REO Current } \\
\text { Production } \\
\text { REO Unuti- } \\
\text { lized Capacity } \\
\text { at Operating } \\
\text { Mines }\end{array}$ & $\begin{array}{l}2,242 \\
280\end{array}$ & $\begin{array}{l}67,265 \\
13,008 \\
2,784\end{array}$ & $\begin{array}{l}2,112,700 \\
13,800 \\
31,599\end{array}$ & $\begin{array}{l}8,844,000 \\
106,670\end{array}$ & $\begin{array}{l}23.90 \% \\
12.90 \% \\
100.00 \%\end{array}$ & 7,143 & 214,315 \\
\hline REE Total & 401 & 15,792 & 45,399 & 138,269 & $32.80 \%$ & 820 & 32,305 \\
\hline Grand Total & & & & & & 7,964 & 246,621 \\
\hline
\end{tabular}

Rare earth production from India (2,800 tonnes REO), Brazil (250 tonnes REO), and Malaysia (280 tonnes REO) has been subtracted from total mine production to prevent double counting as all of these countries produce rare earth from heavy mineral sands, but this small correction does not materially affect the results. As shown in Table B.2, 4-5 times more thorium (nearly 7,143 tonnes per year) might be producible annually as a twice byproduct from heavy mineral sand operations that are mining titanium today. Approximately three times more thorium (820 tonnes per year) might me available from other rare earth operations not included in the cost curves.

Table B.2 has not included some of the potential rare earth mines that were included in the cost and availability curves because Table B.2 only includes operating mines. To capture the thorium that could be produced from potential rare earth mines, these mines capacity is simply added to the 138,269 tonnes of rare earth production per year from Table B.2 . Total REO main product supply has increased over $57 \%$ with the inclusion of these mines. When this potential REO mine supply is added, Main Product Supply Included in Analysis increases by approximately 14 percentage points. Total rare earth supply in this scenario is 173,563 tonnes per year.

\section{Appendix C Hypothetical Thorium Demand Scenarios}

Not only is there a great deal of uncertainly about how a potential thorium fuel cycle might develop, but it is still unclear if thorium will be commercialized. Nevertheless, assessing potential demand for thorium provides context to the quantities of thorium potentially available. So while any demand scenario will be highly speculative, such scenarios are important to understanding potential supply. This appendix develops a simple scenario for demand, and outlines the assumptions used.

A convenient way to characterize the potential total global quantity of thorium demanded annually by a thorium-based fuel cycle is as follows: 


$$
\text { Demand }_{\mathrm{ThO}_{2}} / \text { year }=\frac{\text { TheoreticalMinimumConsumption }}{\text { FuelUtilizationRate }} * \text { OperationalCapacity }
$$

Where theoretical minimum consumption is the quantity of thorium (in tonnes of $99.99 \%$ $\mathrm{ThO}_{2}$ ) required to generate $1 \mathrm{GWe}(1,000 \mathrm{MWe})$ per year if Fuel Utilization Rate was 100\%. Operational capacity measures the total operating capacity of "thorium reactors" ${ }^{14}$ " in GWe per year.

Assuming a thermal efficiency of $40 \%$, theoretical minimum consumption is calculated to be 1 tonne (rounded to the nearest whole tonne) of 99.99\% $\mathrm{ThO}_{2}$ per GWe per year. Fuel utilization may range from approximately 1\%, corresponding with the current uranium fuel cycle, to $100 \%$ corresponding with a continuous recycle with no losses. We will assume a value of $10 \%$ because it is an order of magnitude higher than the $1 \%$ case and one order of magnitude lower than the $100 \%$ case. A value of $10 \%$ for fuel utilization corresponds to a once-through and limited recycle case (Wigeland et al., 2014). This results in a thorium requirement of 10 tonnes per GWe per year. Note that changing the assumption of fuel utilization would scale this requirement linearly. For instance, if a full recycle fuel cycle is employed, bringing fuel utilization to nearly $100 \%$, then the required thorium per GWe of capacity would fall to 1 tonne per year. Readers interested in estimates of thorium requirements for a variety of fuel cycles should refer to Wigeland et al. (2014).

For operational capacity, we assume that the 435 operating reactors around the world are replaced by thorium-consuming reactors after a 60-years life. For simplicity, we further assume that no other reactor construction occurs and thorium-consuming reactors remain operating in perpetuity. These 435 reactors represent $373 \mathrm{GWe}$ of installed capacity, which is the second term in Equation C.1. For simplicity, we assume a capacity factor ${ }^{15}$ of $100 \%$. See Appendix A of Jordan and Eggert (2014) for a more complete detailing of these assumptions. This scenario is depicted in Figure C.1.

Figure C.1 plots annual demand in this scenario on the left axis and cumulative demand on the right axis. In this scenario, the first thorium-consuming reactor comes online in $2029 .{ }^{16}$ While specific dates are given for this scenario, one could also think of them generically, with year 2029 being year 0. Demand rises slowly at first before growth accelerates as a number of reactors retire before finally leveling off. In the year 2074 (or 45 years after the first reactor is converted), the scenario assumes the last reactor converts to thorium and total annual consumption reaches its peak of 3,730 tonnes per year. While one could analyze the thorium requirements at any given level of demand, the peak is particularly relevant in addressing availability because it will dictate the highest level of production needed and in turn require

\footnotetext{
${ }^{14}$ Most conceptualizations of a thorium fuel cycle propose reactors that convert fertile thorium-232 to fissile uranium-233. U-233 can then be used as a "fuel." The term "thorium reactor" is used here for simplicity to refer to a reactor that could consume thorium.

${ }^{15}$ Annual generation divided by capacity

${ }^{16}$ China has recently made commitments to develop thorium reactor technology within a decade, so this a timeline is not unreasonable.
} 
Figure C.1: Assumed Global Thorium Demand Scenario

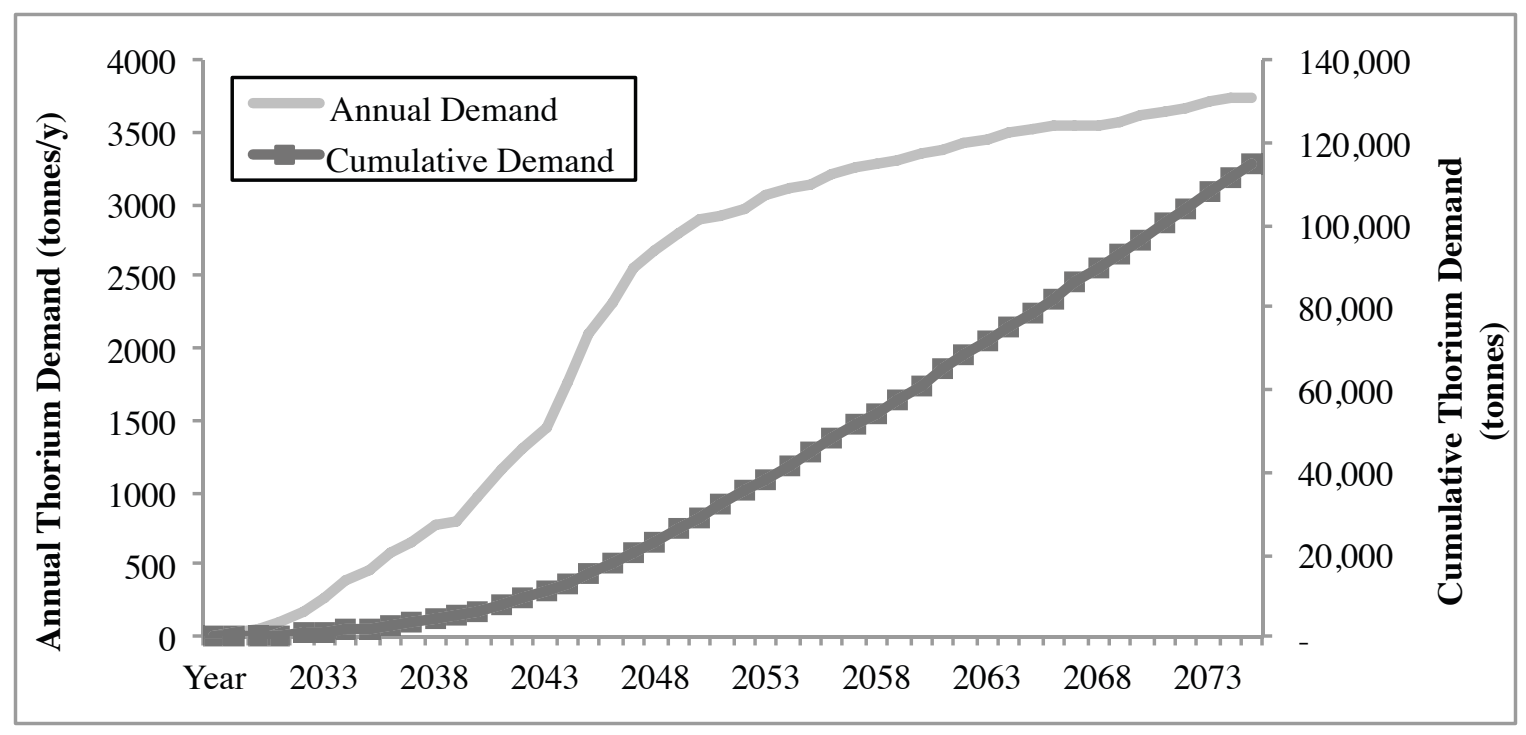

the highest cost resources to be recovered. It is this peak level of demand that we will use in our assessment of the mining-industry cost curve.

Annual demand is not a relevant measure in the context of the cumulative availability curve. For the cumulative availability curve, cumulative demand is needed. Figure C.1 plots cumulative demand through 2074. As with annual demand, there are several ways that one could approach constructing a cumulative demand scenario. We will take a simplified approach and measure cumulative demand at the arbitrary points of 45, 100, 250, 500 years after thorium consumption begins. These later timeframes, 250 and 500 years, are sufficiently far into the future, considering electricity has only in the last century been demanded on a large, commercial scale. The first 45 years in this scenario involves the ramp-up in demand shown in FigureC.1. After 45 years, we will assume annual demand remains constant, as existing thorium-consuming reactors are operated in perpetuity and no addition construction or capacity expansion occurs. Our cumulative demand scenario is shown in Table C.1. Our scenario has cumulative demand reaching over 312,960 tonnes by 2129, or 100 years after the first reactor is converted. By 2529, or 500 years after the first "thorium reactor," cumulative demand reaches $1,804,960$ by the assumptions used in this study. 
Table C.1: Cumulative Demand 45, 100, 250, and 500 Years After First "Thorium Reactor"

\begin{tabular}{ccc}
\hline Scenario Year & $\begin{array}{c}\text { Years From First } \\
\text { "Thorium Reactor" }\end{array}$ & $\begin{array}{c}\text { Cumulative Demand } \\
\text { (tonnes) }\end{array}$ \\
\hline 2074 & 45 & 107,810 \\
2129 & 100 & 312,960 \\
2279 & 250 & 872,460 \\
2529 & 500 & $1,804,960$ \\
\hline
\end{tabular}

